\title{
Visual-Auditive Aspects of Lisung as a relic of Indigenous Community of Kasepuhan Ciptagelar
}

\author{
Tiara Isfiaty $^{1^{*}} \quad$ Imam Santosa $^{1} \quad$ Irma Damayanti $^{1} \quad$ Reiza D Dienaputra $^{2}$ \\ 1.Doctoral Program of Fine Art and Design Institute of Technology Bandung, Indonesia \\ 2.Fakulty of Cultural Science, University of Padjajaran, Indonesia
}

\begin{abstract}
Lisung, the traditional rice pounder is a cultural product of paddy fields of Sundanese community in Indonesia. This research aims to describe the factual condition of visual-auditive aspects of lisung in Kasepuhan Ciptagelar, Banten South, West Java-Indonesia, based on the theory of sensory phenomena. The research focused on how the logic of relationship will built between the visual and auditive aspects of lisung. The relation between the two is suspected to be an aspects that constructed the meaning of lisung culture as the relic of the indigenous community of Kasepuhan Ciptagelar. The research was conducted using the ethnographic method with tracking strategy. The indigenous people of Kasepuhan Ciptagelar were determined as research subjects because they are a group of Sundanese people who still carry on the life of farming in the fields based on the their ancestral heritage called tatali paranti karuhun which are believed as mandatory to be carried out. Lisung is a paddy field cultural relic that accommodates the needs of their domestic rituals, festivals and domestic practices . The results of the research are (1) space as one of the elements of the visual aspects of lisung which results in the presence of new elements, the user element (women) (2) elaboration between the space element and the female element, forming the auditive aspect of lisung (3) visual aspects and auditive aspects of lisung is a unity

Keywords: Visual-auditive aspects, Traditional rice pounder, Sensory phenomena, Indigenous community of Kasepuhan Ciptagelar, Paddy fields culture

DOI: $10.7176 / \mathrm{ADS} / 84-04$

Publication date:August $31^{\text {st }} 2020$

\section{Introduction}

Relic comes from the Latin reliquiae, which means inheritance. For the indigenous people of Kasepuhan Ciptagelar, lisung is one of the important relics of the ancestral heritage which plays an active role in accommodating their various needs both ritual needs, festivals and domestic practices. The presence of lisung is in harmony with the existence of rice plants which are known as the most important food crops for the cultural communities of paddy fields in Indonesia since the days of the ancient Mataram and Sriwijaya kingdoms in the 7 th century AD. Rice plants are believed to be the incarnation of a rice goddess known as Sri. This fact was confirmed by Kalsum (1983) who explained that people in various regions in the archipelago such as Bali, Central Java, East Java and West Java believed the rice story was related to the myth of Sri. The great role of lisung for agrarian Sundanese community was documented since the 15th century AD in Kropak 408 manuscript of Sewaka Darma. In the text can be found the term lisung called gisa. For agrarian Sundanese people, lisung is a relic that was used long ago, as shown in the figure 1 below.
\end{abstract}




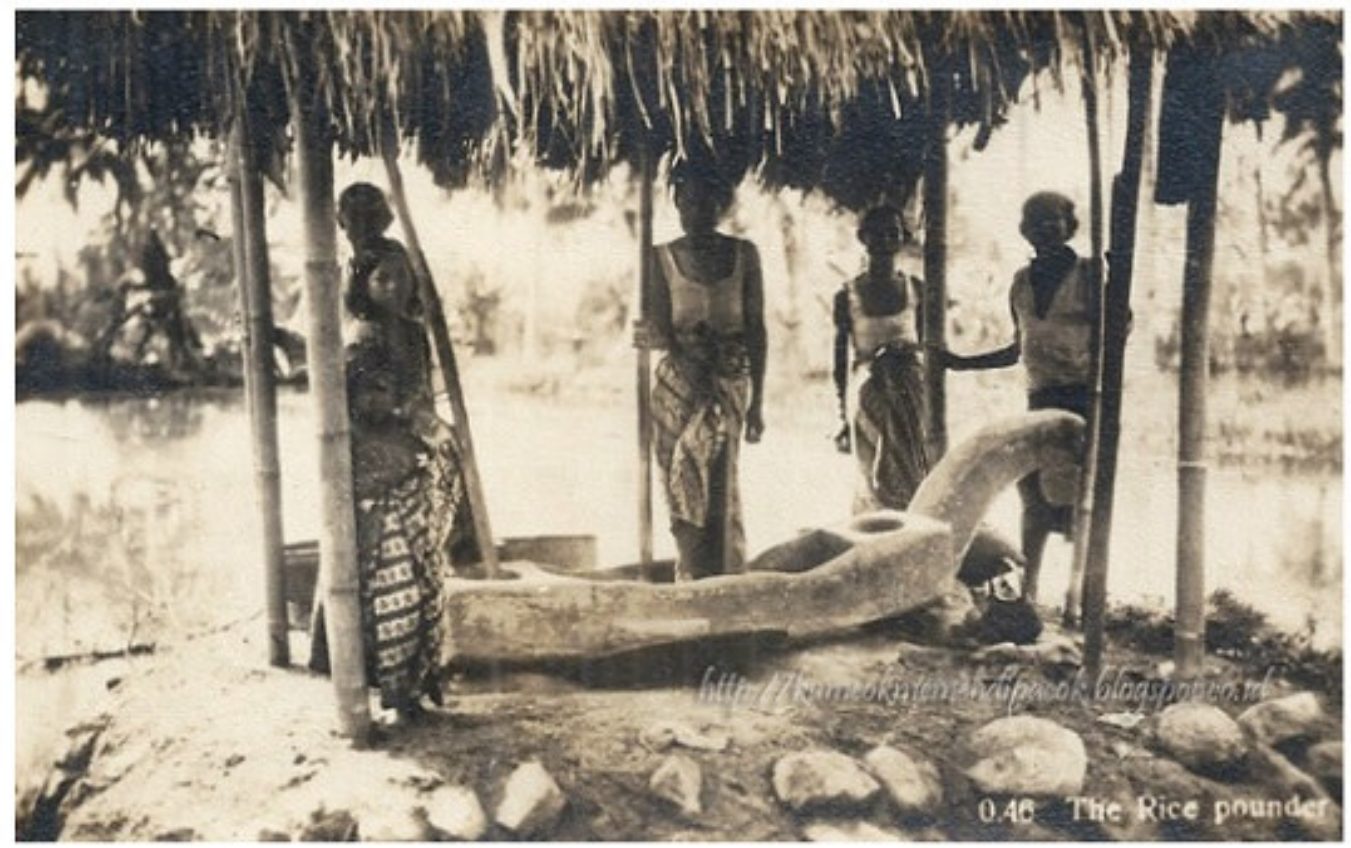

Figure 1. Sundanese women were gathered for rice pounding in the past time

(Source : https://kumeokmemehdipacok.blogspot.com/2016/04/asal-usul-lesung-lisung.html)

Samita (2014) described lisung as a base when carrying out rice pounding. Lisung is made of wood with dimensions between $1.5 \mathrm{~m}$ to $2 \mathrm{~m}$ with a width of about $35 \mathrm{~cm}$. It shape was explained by Sasmita as a boat, elongated and has a space in the middle along the lisung itself called amburan. The mash called halu. It made by elliptical wood the size of an adult's arm. Whereas Soeganda (1982) explained lisung based on its origin. According to him, the term lisung comes from leles, in Sundanese, it means ngurut (massage). Furthermore, Soeganda explained that the process of pounding rice consisted of four stages, namely (1) the stage of ngaguguran, namely the stage of aborting the grain from the stem. (2) the ditampi stage, namely the unhulled grain stage from the stalk to dispose of the dung (3) the dibebek,stage, namely the pounding stage to separate the grain of rice with rice grains. (4) the nyosoh stage, which is the stage of cleaning because usually the grain that has become rice after being dumped still has a lot of dirt. The activity of pounding rice using lisung is similar from nyosoh or sosoh. Nyosoh is the activity of pounding rice that is still skinned to become white rice where is done in a round hole in the lisung, which is located at the front and back ends. Based on field observations, it was found out that in Kasepuhan Ciptagelar, the women made the nyosoh and dibebek stages in the amburan of lisung. The nyosoh stage is carried out in a round hole called a liang. A series of processes for pounding rice can be seen in figure 2. After the last stage is completed, clean rice is put into boboko for processing or stored as daily food supplies for a certain time.

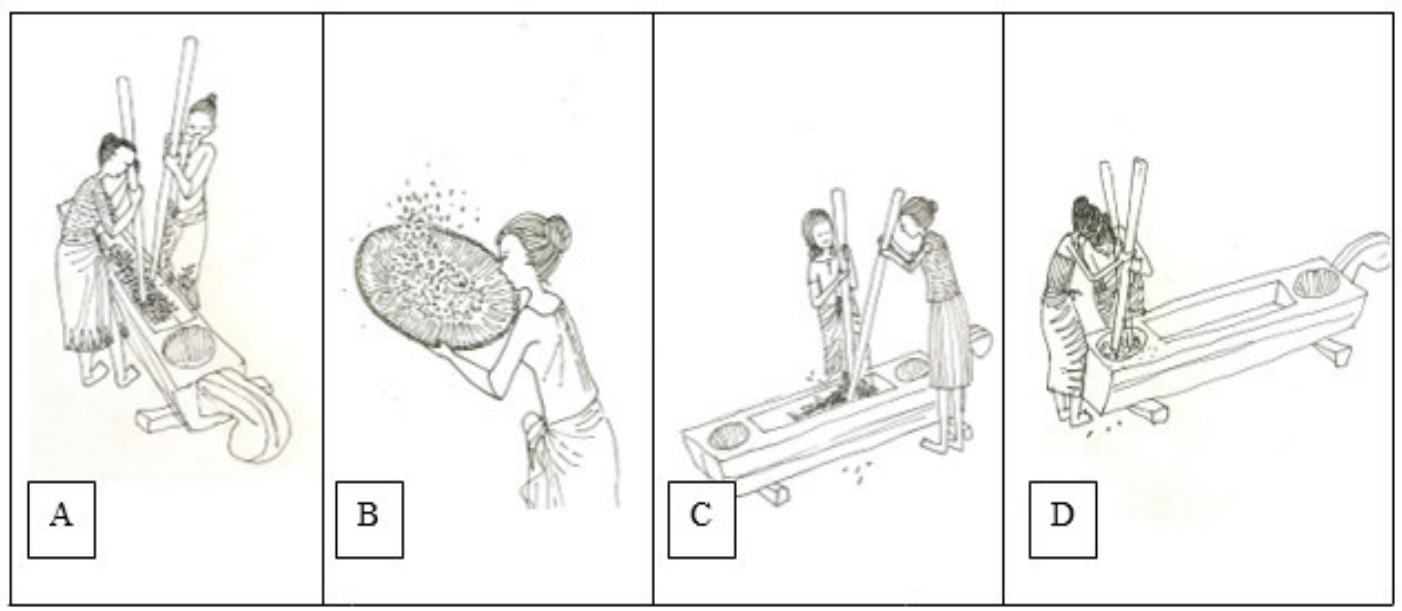

Fogure 2. Illustration of processes of pounding rice processes using lisung. Figure A. The stage of ngaguguran. Figure B. The stage of ditampi. Figure C. The stage of dibebek. Figure D. The stage of nyosoh 
The indigenous community of Kasepuhan Ciptagelar are known as traditional Sundanese groups who inhabit the protected forest area of Mount Halimun in South Banten. They are a group of community who embrace and run their own social system. The obligation to carry out traditional culture of paddy fields based ancestral heritage, has consequences for their belief systems that are implemented in the dominance of ritual implementation as an activity in their lives. Based on the results of direct observations in the field, recorded seven cultural events involving the role of lisung in Kasepuhan Ciptagelar. This fact makes lisung in Kasepuhan Ciptagelar suspected as a media that carries the concept of community thought as a form of understanding, meaning and even worship of rice plants, all its derivatives and their personifications. The visual aspects of lisung in Kasepuhan Ciptagelar generally have the characteristics of forms in accordance with the elaboration of Sasmita and Soeganda (see figure 3)

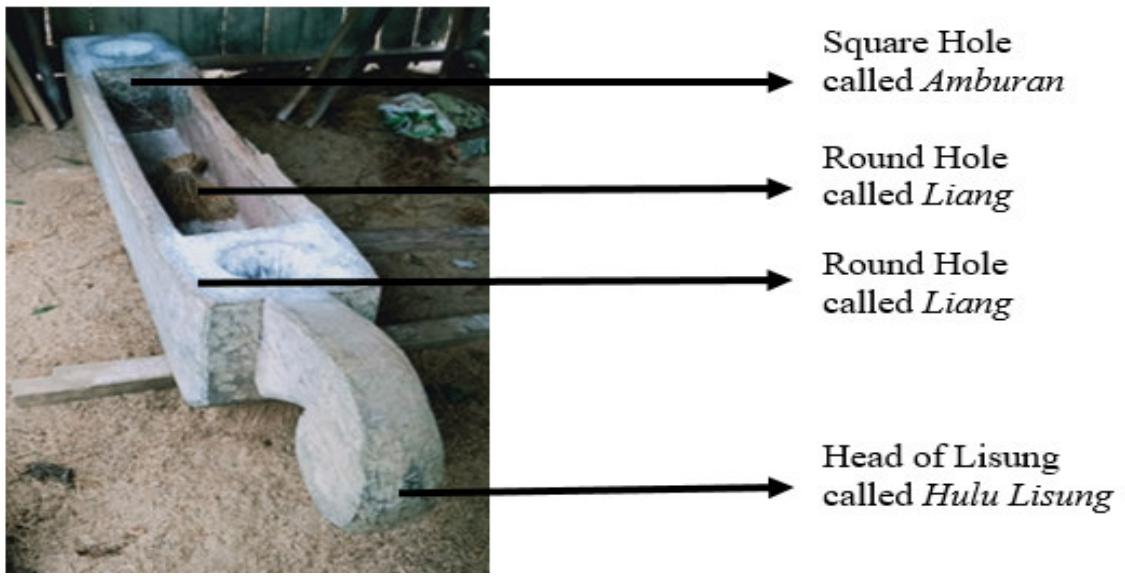

Figure 3. Term of parts of lisung in Kasepuhan Ciptagelar

The belief and actions of the Kasepuhan Ciptagelar indigenous community regarding rice, rice and rice, are facts that are suspected to be the basis of the characteristic aspects of lisung ruparungu there. The visual aspect is the sensory dimension possessed by all objects of human creation, while the auditive aspect is an aspect that is often described independently and separate from the visual aspect. These two aspects are characteristic of an object of human creation in various cultures, especially in Indonesia. This is in line with Soemardjo's (2010) statement regarding Indonesia's primordial society which has character and awareness as a background for material creation both auditive, visual, and also auditive-visual. These two aspects are characteristic of an object of human creation in various cultures, especially in Indonesia. This is in line with Soemardjo's (2010) statement regarding Indonesia's primordial society which has character and awareness as a background for material creation both auditive, visual and also auditive-visual.

\section{Research Method}

This research was conducted using ethnographic as a method. The research strategy is tracking. According to Zimmerman in Coulon (2008), tracking has the sense of walking behind someone's footsteps, meaning that researchers must obtain a familiar view of the social reality that is the subject of their research. The purpose of this research is to describe the factual condition of visual and auditive aspects of lisung as a relic in Kasepuhan Ciptagelar. The relationship between the two is suspected to reveal the meaning of lisung culture according to the way of thinking of the indigenous community of Kasepuhan Ciptagelar

\section{Result and Discussion}

Analysis of the visual-auditive aspects of lisung at Kasepuhan Ciptagelar will be carried out based upon Zuo \& Jones's sensory phenomenon theory. According to Zuo \& Jones in Wiartakusumah (2012) the sensory aspect of an object of creation consists of four elements namely shape, colour, material, texture and space. The elaboration will be done by using the Zuo \& Jones theory adaptation analysis model as visualized in figure 4 


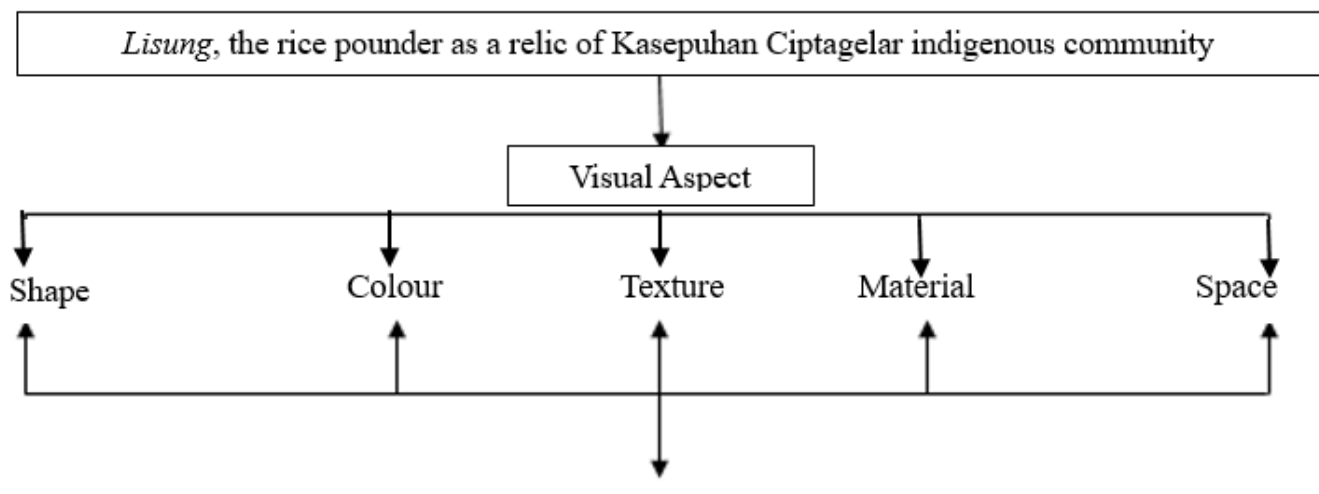

Cultural meaning as an output of beliefs and actions of Kasepuhan Ciptagelar indiogenous community towards rice plants, all their derivatives and personifications

Figure 4. Analysis model of the elements of visual aspects of the Zuo \& Jones theory adaptation

Lisung in Kasepuhan Ciptagelar is placed in a building called saung lisung. It is a building in the form of an open shack (see figure 5). The rice pounder shack's position is placed in the back area of the house and adjacent to the Leuit, an elevated stage-like structure to store rice.

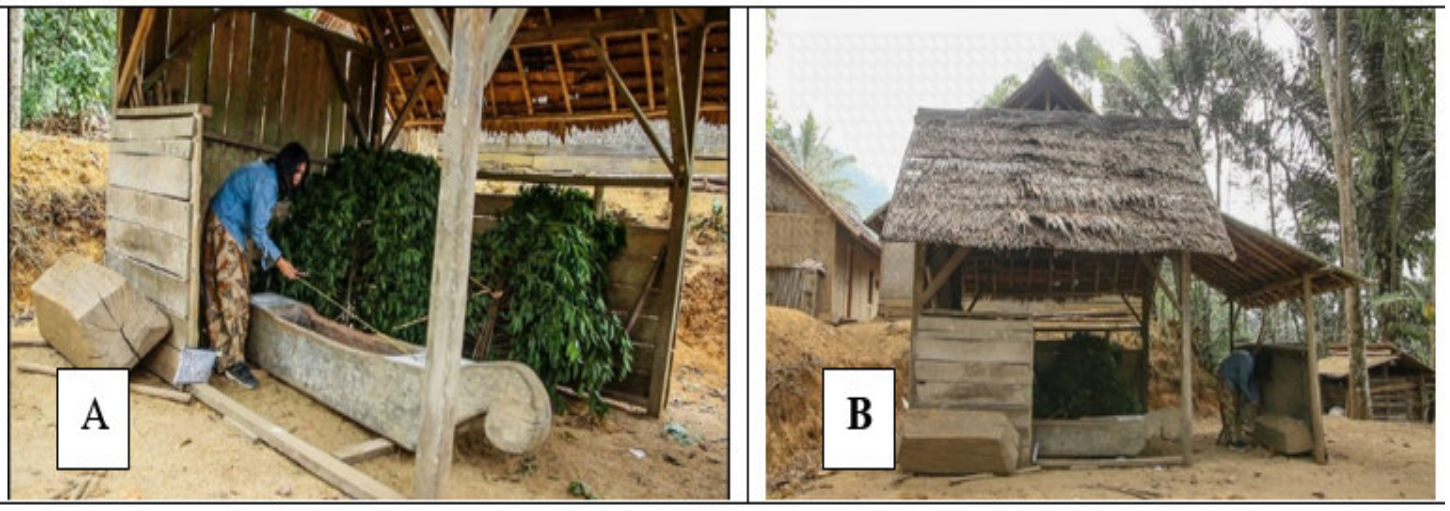

The following is an analysis of the visual aspects of a lisung in the Kasepuhan Ciptagelar traditional village based on the parts of it (body and end of a lisung) and their structure, presented in table 1.

Table 1. analysis of visual aspects of a lisung and halu based on the adaptation of Zuo \& Jones's theory

\begin{tabular}{|c|c|c|}
\hline Lisung & Shape, Colour, Texture, Material & Space \\
\hline & $\begin{array}{l}\text { Shape : } \\
\text { Body of the rice pounder shaped as a Pasagi } \\
\text { (Square) } \\
\text { LxWxH } \\
235-310 \times 40 \times 34-46 \text { in } \mathrm{cm} \\
\text { Pangamburan shaped } \\
\text { Pasagi (Square) } \\
\text { LxWxH } \\
\text { 147x30x } 23 \text { in cm } \\
\text { Liang shaped as an inverted cone that shrinks } \\
\text { downward with a surface diameter of } \\
\text { approximately } 22 \mathrm{~cm} \text {. The depth of the hole is } \\
\text { about } 23 \text { cm } \\
\text { Colour: According to the material } \\
\text { Texture : Rough } \\
\text { Material : Rasamala wood, Puspa wood, Jeray } \\
\text { wood, Ki Anak wood }\end{array}$ & $\begin{array}{l}\text { The visualization above illustrates the } \\
\text { actual floor plan of the rice pounder } \\
\text { in Aki Koyot's Rice pounder shack. } \\
\text { Dotted lines and arrows are indicative } \\
\text { of the space in which pounding } \\
\text { movements occur }\end{array}$ \\
\hline
\end{tabular}




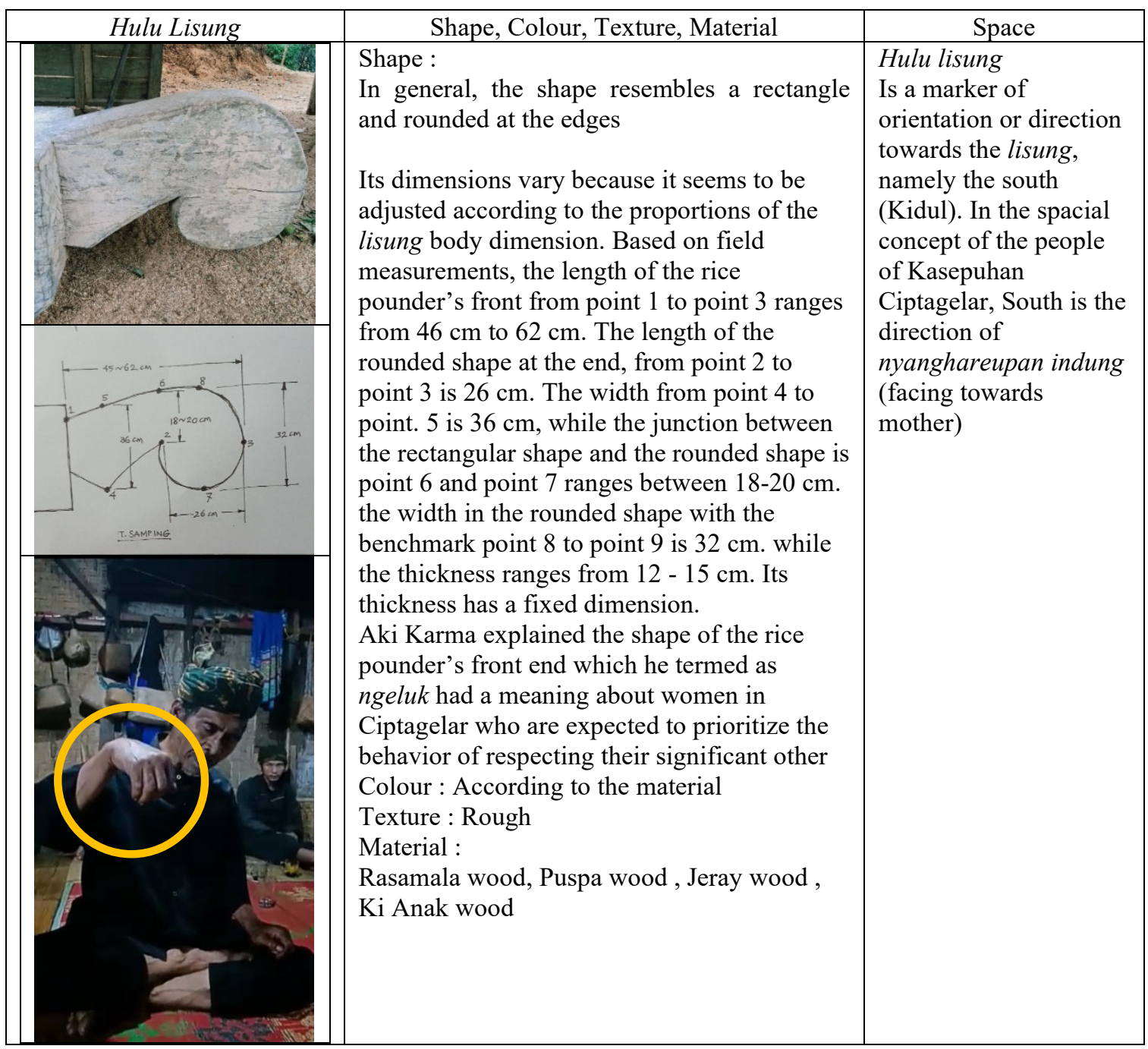




\begin{tabular}{|l|l|l|}
\hline Halu (Rice pestle) & \multicolumn{1}{|c|}{ Shape, Colour, Texture, Material } \\
\hline $\begin{array}{l}\text { Shape : cylinder } \\
\text { Dimensions } \\
\text { Length } 170-173 \mathrm{~cm} \\
\text { Diameter } 4-5 \mathrm{~cm} \\
\text { Colour : According to the material } \\
\text { Texture : rough } \\
\text { Material : Ki Jambe wood, Ki Besi } \\
\text { wood }\end{array}$
\end{tabular}

\section{Conclusion}

Based on the analysis of visual and auditive aspects of lisung in Kasepuhan Ciptagelar, the result is both are the aspects that must be seen as a single unit. The visual auditive aspect of lisung actually becomes an aspect that constructs cultural meaning related to the attitude of worship towards Nyi Pohaci. The cultural meaning that was found was the importance of the role of women in Sundanese society in general and the indigenous community of Kasepuhan Ciptagelar in particular. Sundanese women are the women who have a character that prioritizes the attitude of respect for their life partners. The description of the conclusion is visualized in figure 6 in the form of a schematic chart explaining the integration of the visual sound aspect of lisung as a relique of the karuhun heritage in the Kasepuhan Ciptagelar traditional village. 


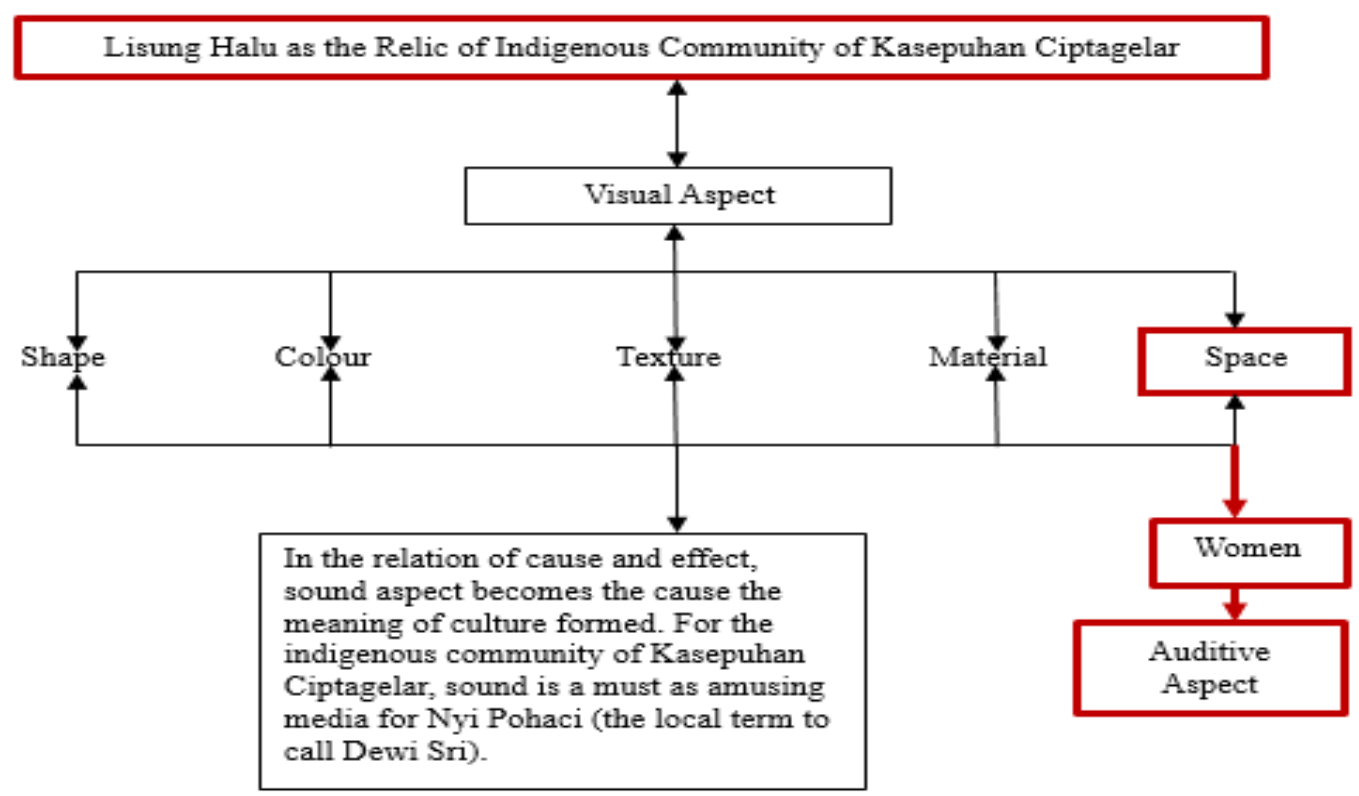

Figure 6. The results of the analysis from visual sound aspects of lisung-halu as the relique of the indigenous community of Kasepuhan Ciptagelar

The process of pounding rice by using lisung - halu in saung lisung is not only a production activity, but a piece of the process to produce rice entities with spirituality quality for later consumption, providing the safety of the lives of people who consume them. The purpose of life safety is a series of processes which in the context of this writing make the visual aspect as the starting point for the series of processes. The space element in the analysis of the halu aspect is the thing that results in the existence of a new element, namely the user element (female) in the aspect of appearance. And when elements of space and elements of women collaborate, sound aspects of lisung are formed, so that the indigenous community of Kasepuhan Ciptagelar are familiar with the term ngagendek (pounding rice with work rhythms and musicals).

\section{References}

Coulon, A (2008) : Etnometodologi, Lengge (Kelompok Genta Press), Yogyakarta

Sasmita, M (2008): Kujang, Bedog dan Topeng dan Kajian lainnya mengenai Budaya Sunda, Pusat Studi Sunda, Bandung

Soeganda, R (1982): Upacara Adat Di Pasundan, Sumur Bandung, Bandung

Sumardjo, J (2010): Estetika Paradoks, Sunan Ambu Press, Bandung

Spradley, J (2007): Metode Etnografi, Tiara Wacana, Yogyakarta

Seri Sundalana (2012): Aspek Visual Budaya Sunda dan Essai-Essai Lainnya Mengenai Kebudayaan Sunda,

Pusat Studi Sunda, Bandung 